explanation for the anti-inflammatory effect of $\mathrm{rHu}$-Epo in patients with RA.

\section{FRI0034 DOES HEAVY CAFFEINE INGESTION AFFECT THE EFFICACY OF METHOTREXATE}

${ }^{1} \mathrm{CM}$ Silke, ${ }^{1} \mathrm{MS}$ Murphy, ${ }^{1} \mathrm{~S}$ Busteed, ${ }^{2} \mathrm{~TB}$ Murphy, ${ }^{3} \mathrm{M}$ Phelan, ${ }^{1} \mathrm{MG}$ Molloy. ${ }^{1}$ Department of Rheumatology, Cork University Hospital; ${ }^{2}$ Department of Statistics, Trinity College, Dublin, Ireland; ${ }^{3}$ Department of Rheumatology, South Infirmary Victoria Hospital, Cork

\subsection{6/annrheumdis-2001.1163}

Background In a proportion of patients methotrexate (MTX) has to be withdrawn because of lack of efficacy or side effects. MTX results indirectly in increased adenosine release. Adenosine, acting at the $\mathrm{A} 2$ receptor, mediates the anti-inflammatory effects of MTX. Caffeine is a non selective adenosine receptor antagonist and reverses the anti-inflammatory effects of MTX in the rat adjuvant arthritis model.

Objectives To see if there was any correlation between withdrawal of MTX due to treatment failure and caffeine ingestion.

Methods Over a 10 month period 91 sequential patients in 2 centres who had ever been on MTX were interviewed. They were classified as either minimal or regular coffee drinkers dependant on whether they drank more or less than 7 cups of coffee per week. Concomitant theophyline medication and tea and cola ingestion were also documented. Doses used varied from 5 to $15 \mathrm{mg}$ weekly (mean $=10.3 \pm 2.75$ ).

Results The proportion of people who have to discontinue MTX is higher in those who are regular coffee drinkers ( $\mathrm{P}$ value $=0.02$ ). In this group the reason for discontinuing was due to treatment failure in $80 \%$ of cases. $90 \%$ of those still on MTX and $74 \%$ of those who discontinued MTX were minimal coffee drinkers.

Conclusion Patients who are on MTX should decrease their caffeine intake as there is a statistically significant increase in treatment failure in those who drink coffee regularly. This may account for the reason that much higher doses of MTX are used in countries with a heavier caffeine consumption.

\section{FRI0035 RISK FACTORS FOR CLINICALLY IMPORTANT UPPER GI EVENTS: THE VIGOUR STUDY}

${ }^{1} \mathrm{C}$ Bombardier, ${ }^{2} \mathrm{~L}$ Laine, ${ }^{3} \mathrm{AS}$ Reicin, ${ }^{4} \mathrm{DR}$ Shapiro, ${ }^{3}$ RS Sperling. ${ }^{1}$ Institute for Work \& Health, Mt. Sinai Hospital, Toronto, Canada; ${ }^{2}$ GI Division, USCSM, Los Angeles; ${ }^{3}$ Clin. Res; ${ }^{4}$ Biostat., Merck \& Co., Rahway, USA

10.1136/annrheumdis-2001.1164

Background The VIGOUR (VIOXX GI Outcomes Research) study was a prospective, randomised, double-blind comparison of rofecoxib (a COX-2 inhibitor) vs. naproxen (a dual COX-1/ COX-2 inhibitor) in $>8000$ patients with rheumatoid arthritis (RA). The study showed that rofecoxib was associated with significantly fewer clinically important upper gastrointestinal (GI) events (perforation, obstruction, bleeding, symptomatic gastric and duodenal ulcers) than naproxen.

Objectives To assess whether the risk reduction in clinically important upper GI events seen with rofecoxib was similar in "high risk" and "low risk" sub-populations; and, to predict the risk of these events based on baseline characteristics.

Methods In the VIGOUR trial, 8076 RA patients expected to require NSAIDs for $>1 \mathrm{yr}$ were randomly assigned rofecoxib $50 \mathrm{mg}$ qd or naproxen $500 \mathrm{mg}$ bid for minimum of 6 -month follow-up. Patients were classified as "low risk" or "high risk" for clinically important upper GI events based on recognised risk factors - age, steroid use, previous history of clinical GI events, and $\mathrm{H}$. pylori sero-status. Relative risk analyses were conducted in both low- and high-risk subgroups. A multifactorial model to predict clinically important upper GI events was developed. Multiple steps in the analysis included: 1 . Covariates were examined in a univariate Cox model; 2 . Factors that trended $(\mathrm{p}<$ 0.20 ) plus treatment were put into Cox model and backwards stepwise regression chose significant $(\mathrm{p}=0.05)$ predictors; and, 3. Interactions between each covariate with treatment were tested one at a time in Cox models.

Results The \% risk reduction (rofecoxib relative to naproxen) of clinically important upper GI events was $88 \%$ in the low-risk subgroup, $51 \%$ in the high- risk subgroup and 54\% in the overall population.

\begin{tabular}{lll} 
Abstract FRI0035 Table 1 & & \\
\hline & Relative risk $(95 \% \mathrm{Cl})$ & p-value \\
\hline $65-74$ vs & $2.37(1.70,3.30)$ & $<0.001$ \\
Uncomplicated vs No Hx of PUBs & $3.08(1.98,4.77)$ & $<0.001$ \\
Complicated vs No Hx of PUBs & $3.73(2.25,6.17)$ & $<0.001$ \\
ARA Class IV vs I/II/III & $2.27(1.10,4.69)$ & 0.027 \\
Prior Hx GI symptoms vs none & $1.81(1.28,2.56)$ & $<0.001$ \\
Prior H2 blocker use vs none & $1.62(1.09,2.43)$ & 0.018 \\
Prior steroid use vs none & $1.59(1.15,2.18)$ & 0.005 \\
Prior NSAID use vs none & $0.57(0.40,0.79)$ & $<0.001$ \\
\hline
\end{tabular}

Risk Factors for Clinically Important Upper GI Events based on Multifactorial Model.

Conclusion (1) The relative risk reduction of GI events in the rofecoxib group was maintained in both the high and low risk subgroups. (2) Multivariate analyses found the risk factors significantly associated with GI events to include age, prior history or clinical GI events (complicated and uncomplicated), disease severity, duration of disease, prior history of GI symptoms, prior use of low dose $\mathrm{H} 2$ blockers, steroids, and NSAIDs.

\section{FRI0036 POPULATION PHARMACOKINETICS (PK) OF ANAKINRA IN SUBJECTS WITH RHEUMATOID ARTHRITIS (RA)}

${ }^{1} \mathrm{~B}$ Yang, ${ }^{1} \mathrm{~J}$ Frazier, ${ }^{2} \mathrm{D}$ McCabe, ${ }^{1} \mathrm{JD}$ Young. 'Pharmacokinetics and Drug Metabolism; ${ }^{2}$ Rheumatology Professional Services, Amgen, Thousand Oaks, USA

10.1136/annrheumdis-2001.1165

Background Anakinra is a recombinant interleukin-1 receptor antagonist that reduces signs and symptoms and slows joint destruction in RA patients in clinical trials. Population PK analysis was conducted on data from RA patients treated with anakinra.

Objectives The objective was to investigate the effect of covariates such as creatinine clearance (CLcr), body weight (WT), age, and sex, on anakinra PK.

Methods Subjects $(n=341)$ received daily SC injections of anakinra at 30,75 , or $150 \mathrm{mg}$ for 6 months; one plasma sample for anakinra measurement was collected from each subject at baseline, and at weeks 1, 4, 12, 20, and 24 before anakinra administration for that day. Plasma samples were analysed for anakinra levels by an ELISA method. Plasma anakinra data were analysed by nonlinear mixed-effects modelling using NONMEM. 